\title{
Monitoring of Selected CBRN Threats in the Air in Industrial Areas with the Use of Unmanned Aerial Vehicles
}

\author{
Anna Rabajczyk *D, Jacek Zboina, Maria Zielecka (D) and Radosław Fellner (D) \\ Scientific and Research Centre for Fire Protection, National Research Institute, Aleja Nadwiślańska 213, \\ 05-420 Józefów, Poland; jzboina@cnbop.pl (J.Z.); mzielecka@cnbop.pl (M.Z.); rfellner@cnbop.pl (R.F.) \\ * Correspondence: arabajczyk@cnbop.pl; Tel.: +48-22-769-32-69; Fax: +48-22-769-33-73
}

Received: 15 October 2020; Accepted: 15 December 2020; Published: 19 December 2020

\begin{abstract}
Unmanned aerial vehicles (UAVs) play an increasingly important role in various areas of life, including in terms of protection and security. As a result of fires, volcanic eruptions, or other emergencies, huge amounts of toxic gases, dust, and other substances are emitted into the environment, which, together with high temperature, often leads to serious environmental contamination. Based on the available literature and patent databases, an analysis of the available UAVs models was carried out in terms of their applicability in air contaminated conditions in industrial areas, in the event of emergencies, such as fire, chemical contamination. The possibilities of using the devices were analyzed in terms of weather conditions, construction, and used materials in CBRN (chemical, biological, radiological, nuclear) threat situations. It was found that, thanks to the use of appropriate sensors, cameras, and software of UAVs integrated with a given system, it is possible to obtain information on air quality at a given moment, which is very important for the safety of people and the environment. However, several elements, including the possibility of use in acidification conditions, requires refinement to changing crisis conditions.
\end{abstract}

Keywords: unmanned aerial vehicles (UAV); CBRN threats; air quality; industrial area

\section{Introduction}

The area of unmanned aerial vehicles (UAVs) is a very dynamic and promising sector, which offers new possibilities and opportunities [1-4]. According to estimates, the drone technology market will reach USD 100 billion in 2020 [5-7]. Most of this market, estimated at 70\%, covers military applications, and the value of the commercial market showing a faster growth rate is estimated at USD 13 billion in 2020. Moreover, PwC experts estimate that the total market of commercial applications in the world amounts to USD 127 billion. Whereas, the size of the industrial drone fleet in Europe and the United States is estimated by the consulting firm BCG at USD 50 billion dollars by 2050, with most of this value expected to be related to drone services and data collection $[5,8]$. Additionally, in Poland, the development of the drone market may be beneficial for the economy and may amount to PLN 310-910 mld, according to the Polish Economic Institute $[9,10]$. The value of the Polish drone market is currently estimated at PLN 140 million, and it is estimated that by 2026 it will increase to over PLN 3 mld $[5,8]$.

Already, drones are used in particular in everyday activities in areas such as agriculture [11], environmental monitoring [12], engineering geology [13], rescue [14,15], insurance and journalism [16]. To monitor chemical hazards and assess the presence of pollutants in the air, detailed data is required to determine the presence of a particular type of pollutant, such as solid particles, volatile organic compounds, combustion products. $\mathrm{CO}_{2}, \mathrm{CH}_{4}, \mathrm{~N}_{2} \mathrm{O}, \mathrm{SO}_{2}$, and toxic organic pollutants polychlorinated 
dibenzodioxins (PCDD), polychlorinated dibenzofurans (PCDF), polychlorinated biphenyls, particles, and nanoparticles of metals [17-19]. When measurements are carried out in hard-to-reach areas or near sources of pollution, the use of UAVs significantly extends the measurement possibilities, enabling a much better spatial and temporal resolution of measurement data compared to the results collected on the basis of tests from the ground or manned aircraft [20-22]. UAV can also be used for testing large areas, including hazardous areas, remote control allows for greater operational flexibility and measurement accuracy [23].

In addition to the areas already in the practice of using UAVs, numerous new potential application areas are undergoing numerous studies [24], such as project work Controlling an autonomous drone with goggles (monocular) [25], analysis, and implementation work. This is also the case in the area of rescue, among others $[14,26]$.

Currently, much attention in conducted research, development work, and analyses is devoted to chemical hazards precisely in the context of support by the available modern technologies of rescue activities. Certain favorable conditions are necessary for the development of this industry. They are at the stage of creation and improvement. Only in recent months, it is possible to indicate some significant changes for the development of this industry, for example:

- publication of the so-called standard scenarios for selected flights in European airspace [27] - they contain the requirements and conditions of flights, which will also apply to UAVs that measure chemicals in range and out of sight,

- implementation by the Polish Air Navigation Services Agency of the PansaUTM drone traffic coordination system in airport controlled zones-thanks to this, operators can quickly check flight possibilities in a given area, digitally submit a flight plan, and obtain a permit to fly, they are also visible to other airspace users, which improves safety [28],

- UAVs testing for the monitoring of refining installations at PKN Orlen in Płock [29],

- large-scale use of UAVs equipped with sensors to fight COVID-19 in industrial and urban areas [30].

The risk of chemical hazards is directly related to the storage, transport, use in the production or manufacture of chemicals. Therefore, this article focuses in particular on the possibilities of using UAVs to monitor chemical hazards (in the meaning of preventive actions) and the possibilities of supporting rescue operations in industrial areas in the event of an adverse event, technical failure, substance release, etc. It should also be noted that in the traditional monitoring system the points are scattered over a large area, sometimes even several kilometers apart. Thus, monitoring concerns the constant measurement of a selected type of pollutant at a given point. If drones are used, it is possible to continuously measure selected pollutants in a given area in a specific time unit. The obtained data make it possible to obtain information on the distribution of pollutants in a given area in a given time unit. This type of monitoring is important especially in crisis situations, such as fire, or in areas where economic activity is carried out with different emission levels, such as landfills, chemical industry.

For this purpose, the following repositories were analyzed: Scopus, ScienceDirect, arXiv, BASE, BazTech, ResearchGate, Academia.edu, Directory of Open Access Journals, DART-Europe, DSpace@MIT, Directory of Open Access Scholarly Resources, Google Scholar. The databases containing research projects implemented under the 7th Framework Program and Horizon 2020 were also analyzed.

\section{Air Monitoring in Industrial Areas}

Atmospheric air and its quality are of significant importance, because on the one hand it determines the functioning of living organisms and the occurrence of various processes, and on the other hand, it is a medium into which various substances are introduced during the emission process. The presence of compounds of different composition and the physical state determines the quality of the air and thereby affects the organisms that live in an area and affects processes. The sources of indoor pollution are practically every process that is carried out in a given area, including printing, photocopying, sanding, mixing, drilling, cutting, painting. Therefore, in industrial areas, depending on the type of technology 
used, processes and activities carried out, compounds that are catalysts of biochemical processes, often allergenic, toxic, and carcinogenic, are emitted including among others nitrogen, sulphur and carbon oxides, ammonia, ozone, heavy metals and their compounds, dusts of various grain sizes and structures, organic compounds such as benzene, acetylene, halogen derivatives, carbon tetrachloride, lead tetraethylide, dimethyl disulphide, phenol, $\mathrm{PAHs}$, and benzo(a)pyrene.

\subsection{Legal Requirements}

In order to ensure the safety of people and processes conducted air monitoring is required, which allows for the assessment of the size and composition of air. In the case of industrial areas, it is important because it allows you to take a number of actions to protect the environment and people, starting from the detection of the threat, measurement of the degree of pollution, assessment of its effects and the method of counteracting pollution and its effects. The collected information is a basic tool in process management and ensuring the safety of people in a given area. The data obtained as part of the monitoring allow for air quality control in relation to the standards in force in a given area, determining the probability of a hazard, e.g., an explosion, and the possibility of influencing the environment, including devices, machines, people working at a site. In the case of industrial areas, monitoring is carried out based on various detection techniques. However, depending on the location of the plant and the nature of the business, the assessment of air quality is based on the relevant laws and regulations applicable in a given area, including local, national, and international (cross-border). It should also be added that monitoring often covers not only the external and internal air of the infrastructure located in the area of an industrial plant (offices, warehouses, technological line), but also external areas, away from the plant, which may be exposed to the negative influence of the emitted substances. Each region with special requirements, such as spas, individual countries, the European Union or international non-governmental organizations such as WHO, have developed a series of regulations that establish recommendations, health standards, and define the objectives of analysis and monitoring for a number of pollutants present in the air. Examples of such regulations include directives issued by the $\mathrm{EU}$, such as:

- $\quad$ Directive 2008/50/EU on ambient air quality and cleaner air for Europe (which includes elements such as for example new air quality objectives for $\mathrm{PM}_{2.5}$ (fine particles) including the limit value and exposure-related objectives, the possibility to discount natural sources of pollution when assessing compliance against limit values, the possibility for time extensions of 3 years $\left(\mathrm{PM}_{10}\right)$ or up to 5 years $\left(\mathrm{NO}_{2}\right.$, benzene) for complying with limit values),

- Directive 2004/107/EC of the European Parliament and of the Council relating to arsenic, cadmium, mercury, nickel, and polycyclic aromatic hydrocarbons in ambient air (Fourth Daughter Directive),

- $\quad$ Directive 2015/1480/EC of 28 August 2015 amending several annexes to Directives 2004/107/EC and 2008/50/EC of the European Parliament and of the Council laying down the rules concerning reference methods, data validation, and location of sampling points for the assessment of ambient air quality,

- Directive 2000/69/EC of the European Parliament and of the Council relating to limit values for benzene and carbon monoxide in ambient air (Second Daughter Directive)—repealed by Directive 2008/50/EC [31].

Attention to the quality of the air we breathe is very important because, according to the data presented by the WHO at the first WHO Global Conference on Air Pollution and Health in October-November 2018 outdoor air pollution is a major cause of death and disease worldwide, and is one cause of the nine deaths worldwide. According to the presented report, as much as $43 \%$ of all lung diseases and deaths from lung cancer can be attributed to air pollution [32].

It should be noted, however, that the requirements for acceptable levels of pollution in many areas apply to different periods of time because the observed health effects associated with different 
impurities occur in different periods of exposure. It is important because it allows determining the possibility of performing work in given conditions and the possibility of health exposure.

In Poland, the Regulation of the Minister of the Environment of 8 June 2018, on the assessment of the levels of substances in the air specifies the methods and scope of assessing the levels of substances in the air. This document also includes requirements for the quality of measurements and other methods of air quality assessment, including mathematical modeling of transport and changes of substances in the air, assessment thresholds for certain substances in the air, and the permissible frequency of their exceeding as well as the minimum number of permanent measuring stations, taking into account emission sources (Journal of Laws 2018 item 1119). In addition, the Regulation of the Minister of Family, Labor and Social Policy on the highest permissible concentrations and intensities of factors harmful to health in the work environment (Journal of Laws 2020 item 61) on the other hand, defines the values of the threshold limit value (TLV) in the air of the working environment. Three types of TLV expressed in $\mathrm{mg} / \mathrm{m}^{3}$ were distinguished:

(1) threshold limit value (TLV) - the weighted average value of concentration, the impact of which on an employee during the 8-h daily and average weekly working time, for the period of his professional activity, should not cause negative changes in health (e.g., ammonia: 14; arsenic: 0.01; molybdenum and its compounds: 4 ; benzo(a)pyrene: 0.002 ; hydrogen chloride: 5 ; phenol: 7.8; crystalline silica: 0.1 ; nicotine: 0.1 ; wood dust, inhalable fraction: 2.0 )

(2) short term exposure limit (TLV-STEL) - the average value of the concentration which should not cause negative changes in the health of the worker, if it occurs in the work environment for no longer than $15 \mathrm{~min}$ and not more often than two times during a work shift, at an interval of not less than $1 \mathrm{~h}$ (e.g., ammonia: 28; molybdenum and its compounds: 10; hydrogen chloride: 10; phenol: 16)

(3) ceiling exposure limit (TLV-CL) - concentration value that cannot be exceeded in the work environment at any time (no limit values, e.g., for ammonia, arsenic, molybdenum, and its compounds, pyrene, hydrogen chloride, phenol, crystalline silica, nicotine, wood dust-inhalable fraction).

Depending on the purpose of the air quality control and monitoring works, it is necessary to use an appropriate tool. Monitoring requires the use of measuring tools with specific requirements, including the ability to carry out measurements in a specific time unit, at an appropriate height, from a specific area, with the same accuracy. If it is necessary to learn about changes taking place in a given area, the current monitoring system, based on several scattered points, is insufficient.

The quantitative and qualitative characteristics of the air inside and around buildings, structures in terms of physicochemical and biological parameters allow determining indoor air quality (IAQ). It is part of the work to be performed to determine the indoor environment quality (IEQ) index [33-35]. The quality of the indoor environment determines the well-being, safety, and work efficiency of people in a given area. Having information about the concentration of certain substances, their change in time and space, it is possible to take appropriate steps to protect the employee and the workplace.

\subsection{Techniques and Tools Used in Monitoring}

Permanent air monitoring is carried out by air quality monitoring stations operating within the state environmental monitoring system. However, in the event of a failure, depending on the needs related to the scale of the hazard, ad hoc measurements are carried out to identify a specific substance. In Poland, these measurements are also carried out by State Fire and Rescue Units of the State Fire Service, such as Regional Inspectorate for Environmental Protection, using mobile devices. The most troublesome for air purity are emitters belonging mainly to the energy and industrial sector, which account for $60-70 \%$ of emissions. In the case of industrial emitters, the term "pollutant discharge" is often used. Measurements of air pollutants can be performed by in situ methods or with the 
use of remote monitoring systems by remote detection or detection at the hazard site and sending measurement data to the database collecting such data [36].

Tubular detectors are used to detect and determine the concentration of certain gases at the point of emission with the use of in situ methods, which enable direct reading of the concentration of a given gaseous pollutant. Depending on the type of analyzer, the following types of devices can be distinguished:

- capillary tube detectors with an electronic reading of the result for determination $\mathrm{O}_{3}, \mathrm{NO}_{2}, \mathrm{NO}$,

- multisensor portable gas detectors for simultaneous detection $\mathrm{O}_{2}, \mathrm{CO}, \mathrm{H}_{2} \mathrm{~S}$, and explosive gases and vapors,

- IR absorption analyzers for detection and concentration determination: $\mathrm{SO}_{2}, \mathrm{NO}_{\mathrm{x}}\left(\mathrm{NO}, \mathrm{NO}_{2}\right.$, $\left.\mathrm{N}_{2} \mathrm{O}, \mathrm{N}_{2} \mathrm{O}_{3}, \mathrm{~N}_{2} \mathrm{O}_{5}\right), \mathrm{CO}, \mathrm{CO}_{2}, \mathrm{HCl}$, and water vapor.

On the other hand, to detect contamination at a distance, optical devices called lidars (LIDAR —Light Detection and Ranging) are most often used or acoustic sodars (SODAR—Sound Detection and Ranging) [37]. Depending on the detection technique used, a number of lidar types are distinguished that are used to perform various measurements necessary in air monitoring, see Table 1.

Table 1. List of technologies used in lidars to perform various measurements necessary in air monitoring.

\begin{tabular}{|c|c|c|c|}
\hline Lidar Type & Detection Technique & Application Range & Ref \\
\hline Scattering & $\begin{array}{c}\text { Radiation-a laser emitting a single wave of a } \\
\text { specific length (one channel); detector-records the } \\
\text { feedback signal (scattering) from the tested object } \\
\text { in the atmosphere }\end{array}$ & $\begin{array}{l}\text { Temperature; } \\
\text { measurements; } \\
\text { boundary layer height; } \\
\text { presence and location } \\
\text { of dust and aerosols in } \\
\text { the atmosphere }\end{array}$ & [38] \\
\hline Raman & $\begin{array}{l}\text { Uses the phenomenon of wavelength shift } \\
\text { (different for different molecules) of scattered } \\
\text { radiation on the object's molecules (gas, aerosols, } \\
\text { dust) caused by inelastic energy exchange between } \\
\text { the molecule and the returning photon (Raman } \\
\text { scattering) }\end{array}$ & $\begin{array}{l}\text { Water vapor; ozone; } \\
\text { atmospheric } \\
\text { temperature profiles; } \\
\text { climate and weather } \\
\quad \text { research }\end{array}$ & [39] \\
\hline $\begin{array}{l}\text { Differential } \\
\text { absorption }\end{array}$ & $\begin{array}{l}\text { Two wavelengths are transmitted: the first } \\
\text { wavelength is inverted to the adsorption line of the } \\
\text { test object (s), the second wavelength is slightly } \\
\text { further from the first and is slightly adsorbed by } \\
\text { the object; } \\
\text { the concentration of chemicals in the atmosphere } \\
\text { can be determined from the differential absorption } \\
\text { coefficient between the two wavelengths }\end{array}$ & $\begin{array}{l}\text { Water vapor; nitrogen } \\
\text { oxides; sulphur oxides } \\
\text { ozone; methane; } \\
\text { ammonia; temperature } \\
\text { measurements }\end{array}$ & [40] \\
\hline Doppler & $\begin{array}{l}\text { Uses the measurement of the Doppler shift } \\
\text { frequency of laser radiation scattered by moving } \\
\text { aerosol or dust particles at wind speed; requires } \\
\text { lasers with a very narrow and stable line }\end{array}$ & $\begin{array}{l}\text { Wind speed } \\
\text { measurement }\end{array}$ & [41] \\
\hline Fluorescent & $\begin{array}{l}\text { The device emits laser pulses of wavelength (in the } \\
\text { range of visible and ultraviolet light) with that } \\
\text { absorbed by the determined substances; the } \\
\text { radiation emitted by the substance is focused by } \\
\text { the telescope and directed towards it; detector }\end{array}$ & $\begin{array}{l}\text { Metal atoms }(\mathrm{Na}, \mathrm{K}, \mathrm{Ca} \text {, } \\
\mathrm{Li}, \mathrm{Fe}) \text { and ions }(\mathrm{Ca})\end{array}$ & [42] \\
\hline
\end{tabular}

A significant advantage of lidars is the possibility of their significant miniaturization, which allows their use in practice when making measurements with the use of UAVs. Such measurement platforms are used to perform accurate measurements of the concentration of pollutants in the air in large areas, including hazardous or hard to reach areas. These measurements are useful not only in monitoring the 
environment but above all in the case of the need to assess chemical contamination in industrial areas emitted by production plants during standard operations and during breakdowns. Gaudio et al. [43] described the results of an experimental campaign carried out in the industrial region of Lamezia Terme, in the Calabria region in southern Italy, with the main purpose of tracing the sources of pollution emitted by urban traffic or factories. The measurements used a lidar/dial system that detects even the first combustion stage on the basis of measuring the content of solid particles. On the basis of the conducted research, it was found that the applied system enables the identification of the source emitting the pollutants.

For remote monitoring by detecting contamination at the point of risk and sending data remotely, point monitors are used to enable sampling, detecting contamination, and sending collected data remotely. The core of a spot monitor is a sensor that converts a physico-chemical signal from a pollutant into an analytical signal, usually an electrical one [44]. The sensors employ a variety of contamination detection mechanisms that can be systematized into the following groups: electrochemical, electrical, gravimetric, thermometric, magnetic, biological, and optical. Electrochemical sensors in the form of electrodes are most often used to detect $\mathrm{O}_{3}, \mathrm{SO}_{2}, \mathrm{NO}_{2}, \mathrm{CO}, \mathrm{CO}_{2}, \mathrm{HCl}, \mathrm{HF}, \mathrm{C}_{\mathrm{n}} \mathrm{H}_{\mathrm{m}}[45,46]$. The electrochemical reaction taking place on the electrode is appropriately selected for the determination of the selected substance. Depending on the mode of operation, there are potentiometric, voltametric, coulometric, and conductometric sensors. Electric sensors that change their parameters in contact with selected substances are used for detection of $\mathrm{NO}_{2}, \mathrm{NO}, \mathrm{H}_{2} \mathrm{~S}, \mathrm{CO}, \mathrm{NH}_{3}$.

To monitor the presence of dust, gravimetric sensors are used, which contain crystals made of piezoelectric material that change the frequency of natural vibrations with the change of mass [47]. The thermometric sensors use the heat of reaction emitted or absorbed as a result of the reaction of the substance being analyzed with the active layer of the sensor [48]. Magnetic sensors operate with the use of the phenomenon of the magnetic field on the paramagnetic quantities of the measured gases [49]. These sensors are used primarily to determine the oxygen concentration in a mixture of other gases.

In biological sensors with a detection, biological, or biochemical element, which is connected to an electric transducer, proteins, enzymes, hormones, microorganisms are most often used as biological detectors. The different types of sensors can be components of multipurpose sensors that are used to monitor pollutant emissions from industrial plants. They can be used for air monitoring with UAVs. This allows for accurate measurements of the concentration of pollutants in the air in large areas, including hazardous or hard-to-reach areas. These measurements are useful not only in monitoring the environment but also in the case of the need to assess chemical contamination in industrial areas emitted by production plants in standard operations and during breakdowns [50-52].

UAVs equipped with measuring devices may soon become a useful tool for general air quality measurements and monitoring. Such solutions also provide new opportunities during rescue operations. Currently, UAVs are used more and more often in the event of technical failures, substance releases, and other local hazards. The scope and method of using these solutions also in rescue are subject to significant changes, new possibilities of application are revealed and use. Numerous research and development works are carried out in the field of using UAVs. One of the projects carried out under international cooperation is the project "Drones4Safety-Inspection Drones for Ensuring Safety in Transport Infrastructures" (Horyzont2020). The project aims to increase the security of the European civil transport system by developing a swarm of autonomous drones specialized in the inspection of railway and road infrastructure [53].

Another example is the "LABYRINTH" project (Horizon2020), which is devoted to creating a flight planning system that uses communication between drones and advanced algorithms to avoid collisions [54]. However, as part of the project "Design and construction of a family of special purpose unmanned aerial vehicles" (The National Centre for Research and Development, Poland), it is planned to develop seven UAV platforms with dedicated sensors, including visible and infrared light, as well as sensors for assessing environmental contamination with chemicals [55]. They concern both the structure and parameters of UAV, its control, autonomy, as well as the use of measuring devices, 
image transmission, etc. It is a dynamic industry for which legal foundations and standardization works are carried out. In June 2020, ISO published four international standards [56-59]. On the other hand, the ISO/TC 20/SC 16 Committee is working on 25 other standards. It is also worth mentioning that European UAVs will have to have a unique physical serial number compliant with standard "ANSI/CA-2063 Small Unmanned Aerial System Serial Numbers".

The fact is, however, that dedicated formal bases for use as well as standardization or standardization documents and guidelines are becoming more and more urgent [60] concerning, inter alia:

- use of UAVs during incidents involving hazardous materials,

- transport of hazardous materials and samples with UAVs,

- methods of decontamination of UAVs exposed to pollutants and other chemicals.

At the same time, it is recommended to continue research efforts aimed at the development and implementation of durable sensors, resistant to harsh environmental conditions [61].

\section{Characteristics of Unmanned Aerial Vehicles}

UAS (unmanned aerial systems), also known as drones or remotely piloted aircraft systems, are systems consisting of an unmanned aerial vehicle (UAV), a communication link, a ground control station (GCS), payload, software, and an operator. Thanks to the current technology, UAVs may be controlled from the ground, remotely, partially, or fully autonomous. UAVs are classified in various ways, including e.g., operational range, weight, or configuration. Currently, however, there is no one universal, recognized classification that would be universally used.

One of the essential elements in the selection of UAVs for work are parameters of the device and the skills of its operator, which determine the ability to perform specific, desired activities. Dedicated devices are used to conduct measurements, they have sets of sensors and equipment, as well as software often constituting a proprietary solution addressed to a given device such as FLIR VueLink ${ }^{\mathrm{TM}}$, DRIMS2, Atmon FL Ground Unit [62-64], for recording the results of their analysis and transmitting information and signals.

For the purpose of monitoring chemical hazards and threats in industrial areas, indispensable components include at least:

- thermometer-makes it possible to determine whether the ranges specified by the manufacturer are not exceeded and whether there is a risk, e.g., faster discharge of the batteries as a result of low temperature,

- pyrometer-enables remote point temperature measurement of an object, e.g., a tank,

- hygrometer-allows measurement of humidity and determining whether it does not exceed the level that may damage electronic systems or deteriorate radio communication,

- altimeter (e.g., barometric) - allows to compare the concentrations of substances at different heights,

- GNSS receiver-determines precise position of the UAV,

- transponder-enables detection and recognition of UAVs by other airspace users and air traffic services,

- navigation and warning lighting — enables safe flight at night,

- transmitters, radio signal receivers, antennas-they enable the control of UAVs on long distances.

\section{Sensors}

Chemical substances sensors as well as acoustic and optical sensors, which can be used depending on the purpose of the monitoring, are crucial through the monitoring (Table 2). Apart from the monitoring objective, the UAV system itself and the software have also great importance. The sensors must be compatible with the selected UAV model. 
Table 2. Characteristics of selected sensors.

\begin{tabular}{|c|c|c|c|c|c|}
\hline Sensors & Parameters & Application & Advantage & Disadvantage & Ref \\
\hline \multicolumn{6}{|c|}{ Infrared sensors } \\
\hline Zenmuse XT2 & $\begin{array}{l}\text { Resolution: } 640 \times 512 \\
\text { or } \\
336 \times 256 \\
\text { Frequency: } 30 \mathrm{~Hz} \\
\text { IP: } 44 \\
\text { Mass: } 629 \mathrm{~g} \\
\text { Temperature detection } \\
\text { range: }-40-550{ }^{\circ} \mathrm{C}\end{array}$ & $\begin{array}{l}\text { Fire } \\
\text { Solar panel } \\
\text { inspections } \\
\text { Research } \\
\text { relating to } \\
\text { hazardous } \\
\text { materials } \\
\text { power industry } \\
\text { Agriculture } \\
\text { Building } \\
\text { inspections } \\
\text { Rescue }\end{array}$ & $\begin{array}{l}\text { Numerous additional } \\
\text { functions: } \\
\text { Temperature alarm } \\
\text { Tracking of the } \\
\text { warmest object } \\
\text { Overlay an RGB over } \\
\text { thermal image } \\
\text { Freezing the view on a } \\
\text { specific object } \\
\text { View of a specific } \\
\text { temperature spectrum } \\
\text { band }\end{array}$ & & [65] \\
\hline \multicolumn{6}{|c|}{ Magnetometers } \\
\hline The AirBIRD & $\begin{array}{l}\text { Mass: } 3.5 \mathrm{~kg} \\
\text { Minimum cruising } \\
\text { speed: } 10 \mathrm{~m} / \mathrm{s} \\
\text { Operating time: } 1.5 \mathrm{~h} \\
\text { GPS accuracy: } 0.7 \mathrm{~m} \\
\text { Sensitivity: } 0.022 \mathrm{nT} \\
\text { Refreshing: } 1 \mathrm{~Hz} \\
\text { Accuracy: } \pm 0.1 \mathrm{nT} \\
\text { Tolerance gradient: } \\
50,000 \mathrm{nT} / \mathrm{m}\end{array}$ & $\begin{array}{l}\text { Measurements } \\
\text { of the magnetic } \\
\text { field and its } \\
\text { changes }\end{array}$ & $\begin{array}{l}\text { High measurement } \\
\text { accuracy } \\
\text { Measurements } \\
\text { broadcast live by radio } \\
\text { to the GCS }\end{array}$ & $\begin{array}{l}\text { The test lead } \\
\text { makes it } \\
\text { difficult to use } \\
\text { in the field with } \\
\text { obstacles } \\
\text { Difficult } \\
\text { operations } \\
\text { during high } \\
\text { winds }\end{array}$ & [66] \\
\hline $\begin{array}{c}\text { The } \\
\text { MONARCH }\end{array}$ & $\begin{array}{l}\text { Plane with built-in two } \\
\text { magnetic field sensors } \\
\text { Sensitivity: } 0.022 \mathrm{nT} \\
\text { Refresh: } 1 \mathrm{~Hz} \\
\text { Accuracy: } \pm 0.1 \mathrm{nT} \\
\text { Gradient Tolerance: } \\
50,000 \mathrm{nT} / \mathrm{m}\end{array}$ & $\begin{array}{l}\text { Measurements } \\
\text { of the magnetic } \\
\text { field and its } \\
\text { changes }\end{array}$ & $\begin{array}{l}\text { No system cable } \\
\text { required } \\
\text { Possibility of flight in } \\
\text { worse weather } \\
\text { conditions } \\
\text { The ability to fly with a } \\
\text { small amount of } \\
\text { terrain obstacles }\end{array}$ & Cannot hover & [67] \\
\hline \multicolumn{6}{|c|}{ Sonars } \\
\hline MB1242 & $\begin{array}{l}\text { Interface: I2C } \\
\text { Supply voltage: } 3-5.5 \\
\text { V } \\
\text { Frequency: } 42 \mathrm{kHz} \\
\text { Refresh rate: } 10-40 \mathrm{~Hz} \\
\text { Weight: a few grams }\end{array}$ & $\begin{array}{l}\text { Distance } \\
\text { measurement } \\
\text { Automatic } \\
\text { flights }\end{array}$ & $\begin{array}{l}\text { Low power } \\
\text { consumption } \\
\text { Low interference } \\
\text { impact } \\
\text { Easy to mount } \\
\text { Low price }\end{array}$ & $\begin{array}{l}\text { Reliability } \\
\text { (certainty) of } \\
\text { measurements } \\
\text { Low range (up } \\
\text { to several } \\
\text { meters) }\end{array}$ & [68] \\
\hline \multicolumn{6}{|c|}{ Multispectral sensors } \\
\hline RedEdge-MX & $\begin{array}{l}\text { Weight: } 231.9 \mathrm{~g} \\
\text { Battery voltage: } \\
4.2-15.8 \mathrm{~V} \\
\text { Power: } 4 \mathrm{~W} \text { peak } 8 \mathrm{~W} \\
\text { Spectral bands: Blue, } \\
\text { green, red IR } \\
\text { Frequency: } 1 \mathrm{~Hz} \\
\text { Interfaces: Serial, } \\
\text { Ethernet, removable } \\
\text { Wi-Fi, GPS, SDHC }\end{array}$ & $\begin{array}{l}\text { Measurements } \\
\text { of different } \\
\text { objects in } \\
\text { different light } \\
\text { ranges can give } \\
\text { information on: } \\
\text { Substrate } \\
\text { moisture } \\
\text { Condition/conditi } \\
\text { of plants } \\
\text { Temperature }\end{array}$ & $\begin{array}{l}\text { Broad range of } \\
\text { application } \\
\text { Relative low mass } \\
\text { on }\end{array}$ & High price & [69] \\
\hline
\end{tabular}


Table 2. Cont.

\begin{tabular}{|c|c|c|c|c|c|}
\hline Sensors & Parameters & Application & Advantage & Disadvantage & Ref \\
\hline \multicolumn{6}{|c|}{ Radiation sensors } \\
\hline DroneRad & $\begin{array}{l}\text { Resolution: } 1 \mu \mathrm{R} / \mathrm{HR} \\
\text { Interface: RS-232, USB } \\
\text { (optional) } \\
\text { IP: } 64 \\
\text { GPS measurement } \\
\text { location }\end{array}$ & $\begin{array}{l}\text { Measurement } \\
\text { of gamma } \\
\text { radiation and } \\
\text { X-rays } \\
\text { (optional } \\
\text { number of } \\
\text { neutrons) }\end{array}$ & $\begin{array}{l}\text { Easy to install } \\
\text { Wireless } \\
\text { Detection of the type of } \\
\text { radioactive substance } \\
\text { Battery powered }\end{array}$ & & [70] \\
\hline \multicolumn{6}{|c|}{ Toxic substances sensors } \\
\hline $\begin{array}{c}\text { Smart Cable } \\
\text { Air }\end{array}$ & $\begin{array}{l}\text { Battery power: } 1.5-3.6 \\
\mathrm{~V} \\
\text { Power: } 2 \mathrm{~mW} \\
\text { Interface: } \mathrm{I} 2 \mathrm{C} \text { or } \\
\text { SENSIBUS } \\
\text { Substances to be } \\
\text { measured: } \\
\text { - } \mathrm{NH}_{4} \\
\text { - } \mathrm{NO}_{2} \\
\text { - Alcohol } \\
\text { - Air pollutants, } \\
\text { including } \\
\text { flammable ones, } \\
\text { Cigarette smoke }\end{array}$ & $\begin{array}{l}\text { Measurements } \\
\text { of substances in } \\
\text { quantities } \\
\text { endangering } \\
\text { human health }\end{array}$ & $\begin{array}{l}\text { Low power } \\
\text { consumption } \\
\text { Additional } \\
\text { measurement of } \\
\text { humidity and } \\
\text { temperature }\end{array}$ & $\begin{array}{l}\text { Requires } \\
\text { adaptation to } \\
\text { the drone }\end{array}$ & $\begin{array}{l}{[71,} \\
72]\end{array}$ \\
\hline MUVE C360 & $\begin{array}{l}\text { Weight: } 680 \mathrm{~g} \\
\text { Measured substances: } \\
\mathrm{CO}, \mathrm{Cl}_{2}, \mathrm{O}_{2}, \mathrm{NO}_{2}, \mathrm{H}_{2} \mathrm{~S} \text {, } \\
\mathrm{SO}_{2}, \text { lower explosive } \\
\text { limit IP: } 43 \\
\text { Battery power: } 24 \mathrm{~V}\end{array}$ & $\begin{array}{l}\text { Measurements } \\
\text { of substances in } \\
\text { quantities } \\
\text { endangering } \\
\text { human health }\end{array}$ & $\begin{array}{l}\text { Results transmitted } \\
\text { live }\end{array}$ & $\begin{array}{l}\text { Requires the } \\
\text { use of a specific } \\
\text { UAV } \\
\text { Power supply } \\
\text { from UAV } \\
\text { No thresholds } \\
\text { or warnings }\end{array}$ & [62] \\
\hline
\end{tabular}

Source: own study based on technical data.

The use of selected sensors and the UAV itself in a specific environment with high emissions of toxic substances requires their additional adaptation, that is, inter alia, ensuring an appropriate IP protection level (International Protection Rating). One of the basic issues in these conditions is the resistance of UAVs and used measuring devices to weather conditions, as well as taking into account the presence of temporary or permanent chemical substances in a given zone. For example, in air, some oxides, when reacted with water vapor, can form corrosive substances, such as acids, which can undoubtedly be destructive to housing components. Therefore, adaptation to work in such conditions should also apply to elements such as ground control stations/RC apparatus, flight parameter display screen and camera view, gimbal with a camera, goggles for viewing the image, additional mobile antennas increasing the range. In addition, consideration must be given to the possibility of certain conditions posing a risk of temporary or continuous occurrence of potentially explosive zones, which poses further challenges for UAVs and their equipment. Equipment and systems intended for use in potentially explosive atmospheres must meet certain basic requirements. Ensuring compliance of the UAV and its dedicated equipment with ATEX directive may cause a technical problem that will result in the limitation of use in potentially explosive areas [73]. UAVs equipped with electric motors and various sensors and electrical components may be a potential source of ignition due to the material from which they were made and their construction [74].

The present limitations include, inter alia, the widespread use of a composite housing that accumulates electrostatic charges, and the traditional use of spraying an antistatic agent on a surface 
may not be feasible or may damage other systems. Thus, the development or adaptation of a drone to ATEX requirements (in the field of intrinsic safety) is currently a complex challenge, both in terms of science and technology (development of the solutions themselves), as well as business (implementation costs).

One of the few examples of UAVs currently meeting the requirements of the ATEX directive is the LE 4-8X [75], which was used to detect gas leaks and damage to the thermal insulation of tanks in the Guiana Space Centre. The conceptual work, the appropriate risk assessment procedure, and the adaptation of this product was a great challenge and took as long as 18 months [76]. It was necessary to adapt all electrical and electronic systems, replace the housing with a material with a specific thermal resistance, modify the wiring, replace elements, such as carbon fiber propellers that were replaced with wooden ones to prevent static electricity. The introduced changes allowed for the adaptation of the UAV to work in the 2nd hazard zone classified according to the ATEX directive, i.e., where it is unlikely that the potentially explosive atmosphere (consisting of a mixture with air of flammable substances in the form of gas, vapor, or mist) will occur in the performance of ordinary activities, and if it occurs for a short period [77].

UAVs allow to locate a source of threat, remotely measure a toxic and hazardous substance, transmit the image at specific distances to the rescue operation control station, and visualize the measurement results in real time. Therefore, they enable faster identification of the situation and thus the possibility of making better decisions regarding the use of human and material resources, as well as conducting rescue operations. The applications of these solutions are already possible in this area, and in the future more technologically advanced solutions will be available, which will extend the scope of application in the areas of impact of various substances, including explosive atmospheres.

Applications of these solutions are already possible in this area, and in the future, more technologically advanced solutions will probably be available, which will extend the scope of application in the areas of impact of various substances, including explosive atmospheres.

It should be added, however, that one of the most important issues in the conducted works is the need to obtain an accurate measurement, consistent with the actual state present in a given environment. The obtained result is conditioned by many factors, including imperfection of the measuring instruments used, variability of the measured physical quantity. Knowledge in this area is necessary, as it allows to determine whether the obtained results make sense, whether they provide a basis for the development of credible and reliable information and tools to counteract the occurrence of these threats. The operator, depending on the purpose of the research, must apply an appropriate measurement methodology, taking into account the sensor parameters in relation to the analysis of the environment in which the measurement is carried out, or the size of a possible error. Hence, it is necessary to take into account the process of verification of the measurement accuracy, validation of the developed solution in given environmental conditions, for a given concentration range of the selected analyte.

Monitoring chemical hazards, and thus using UAVs to support rescue operations, is one of the areas of current research and a potential area of mass application of this technology and UAV capabilities in the near future. In the scientific literature, attention is drawn to the aspects necessary for the safe use of UAVs in rescue, such as appropriate, adapted to a given type of UAVs mission, operator training, risk analysis, adaptation of UAVs to autonomous flight. This is important for flights within the operator's line of sight and becomes more specific when flying out of sight. UAVs are not immune to radio signal interference or difficult weather conditions. Their disadvantages also include the relatively short flight time of the currently offered UAVs, especially in the case of multirotors. The necessity to interrupt the flight and measurements, landing, battery replacement, and re-take off limit the usefulness of UAVs use during rescue operations. Therefore, modernization of UAVs towards full autonomy (e.g., automatic landing and battery replacement) and relieving the operator (rescuer) is increasingly important for the possibility of using it in rescue operations [77], when immediate information on air quality, pollutant identification, and emissions is essential. 


\section{Application of UAV for Air Quality Assessment}

UAVs equipped with appropriate sensors are increasingly being successfully used in rescue operations. Visible light and infrared cameras are most often used during and after rescue operations. This was the case with the gas explosion and the fire of the gas pipeline in Murowana Goślina in 2018 [78] or the gas explosion in Janków Przygodzki in 2013 [79]. Current and constant monitoring of selected compounds and temperature, carried out by drones, allowed for taking appropriate measures, minimizing the further development of environmental contamination.

It should be noted that in the scientific literature there are relatively a few studies devoted to operational monitoring of threats in the chemical industry with the use of unmanned aerial vehicles. Restas A. distinguished two basic possibilities of its use [80]:

(1) to support preventive actions-during airborne inspections of hazardous materials transport and monitoring industrial facilities or installations,

(2) responding to accidents involving hazardous substances-reconnaissance in the event of an accidental leakage of hazardous substances.

The researcher draws attention to the advantages of using UAVs compared to the traditional operation of chemical rescue units-faster time of launching and delivering the image from the scene without exposing firefighters to danger. Traditional chemical reconnaissance means preparing measuring equipment, putting on protective clothing and a breathing apparatus along with starting the measuring devices, which obviously takes more time than the preparation and measurement flight of the UAV. Moreover, the protective clothing may obstruct movement or even prevent thorough reconnaissance [80]. It should be noted, however, that the effective and efficient use of UAV requires meeting several conditions at the same time. These include, among others: fast transmission of high-quality images from the camera, favorable weather conditions for flights, appropriate training, and qualifications of operators.

Particular difficulties may arise when it is necessary to use UAV inside facilities, such as rooms, tanks. Inside the facility there may be flammable dusts or flammable materials, pyrophoric compounds that react with water or oxygen, and toxic compounds. In such an environment the system may be damaged or contaminated. The need to decontaminate the UAV after use requires careful assessment and planning. In addition, remote devices may be out of the pilot's line of sight and internal obstacles may present a difficult flight path. In such a situation, an action plan should be defined before starting operations in the event of a shutdown of the UAV inside the facility [52].

The possibility of using drones to minimize the threat to life and health due to the emission of harmful compounds into the atmosphere was also noticed by the Austin Powder company, which deals with explosives. The company aims to minimize the emissions of toxic $\mathrm{NO}_{\mathrm{x}}$ that can be released into the atmosphere during mining operations. To this end, scientists at the Rochester Institute of Technology are developing ways to use drones to quantify the $\mathrm{NO}_{\mathrm{x}}$ contamination produced by explosions. They plan to capture the volume of the $\mathrm{NO}_{\mathrm{x}}$ cloud by placing multiple drones with synchronized cameras around the explosion, and fly the drone directly into the cloud left by the explosion to measure the gas concentration with special equipment [81].

Chemical companies are showing increasing interest in the use of drones to protect and counteract threats. Currently, drones are used primarily for taking photos, monitoring surfaces, however, due to the emerging technological solutions, research is being undertaken in the field of plant monitoring, for example to detect gas leaks [82]. The Defense Threat Reduction Agency (DTRA) is researching the placement of chemical weapons sensors on drones. One of the biggest challenges in developing this drone monitoring system is integrating the sensor software with the navigation electronics for drones so that if a suspicious relationship is detected with the drone it can be maneuvered into the cloud for optimal detection and data collection [82].

Drones can be used for individual detection, i.e., to measure a selected pollutant at a selected point, but they can also be used in an air quality monitoring system, in difficult, dangerous, health, 
and life-threatening areas or in standard conditions. Drones are used for ongoing monitoring works, including measurement and monitoring of pollutants emitted, especially in the autumn-winter-summer period. Due to the fight against smog, standard monitoring based on measurement points is insufficient. More and more often, the roads are used to measure smog pollution, including $\mathrm{PM}_{10}$ and $\mathrm{PM}_{2.5}$. Ongoing monitoring of a given area, based on drones, is a tool to combat the improper process of heating houses or other activities contributing to the increased risk of smog.

An example is the Aviation Atmosphere Monitoring System by Pelixar S.A., which is used, inter alia, to detect sources of emissions resulting from the combustion of forbidden substances, to determine the size of the smog cloud, the directions of its movement, the place of its condensation and the prediction of the phenomenon. Depending on the version, the Pelixar LMA drone is equipped with a module for remote reading and recording of parameters: suspended $\mathrm{PM}_{2.5}$ and $\mathrm{PM}_{10}$ dust, thermometer, hygrometer, GPS position, video camera with 10x optical zoom, video transmission in FHD resolution. The concept of measuring pollutants that generate smog, including the location of the emission source, based on drones, has been introduced in cities such as Gdynia and Elblag (Poland) [83].

An interesting solution is also Scentroid DR1000, which can be used for sampling and analyzing the surrounding air up to $150 \mathrm{~m}$ above ground level. It gives the opportunity to monitor more than 30 different pollutants, including $\mathrm{H}_{2} \mathrm{~S}, \mathrm{CH}_{4}, \mathrm{CO}_{2}, \mathrm{SO}_{2}$, VOCs, and particulate matter $\left(\mathrm{PM}_{10}, \mathrm{PM}_{2.5}\right.$, and $\mathrm{PM}_{1}$ ). The Scentroid DR1000 laboratory drone also allows to safely collect air samples required for laboratory analysis, which is important especially in places that are inaccessible or difficult to access, or in places that threaten the operator's health and life [63].

One of the applications of UAVs in the area of CBRN (chemical, biological, radiological, and nuclear) threats is the measurement of radioactive radiation. The method was successfully used during the accident at the Fukushima nuclear power plant. The unmanned helicopter during programmed autonomous flights was used to map the radiation distribution and illustrate the movement of the radioactive cloud. It also made it possible to measure radiation in areas that are difficult to access for units with portable meters. Marturano et al. [84] simulated complex scenarios that took into account increased levels of radioactivity as occurred during the Chernobyl and Fukushima nuclear power plants failures. In subsequent emergencies of this type, an accurate mapping of the radioactive cloud can provide invaluable input for mathematical models determining the dispersion of radioactivity in time and space. This information can be a valuable input to predictive models and decision support systems, providing valuable guidance on the safe intervention of first responders or the subsequent need to evacuate affected regions.

Dutch crisis management firm Trimension ran a three-day the Trimodex 2 exercise, sponsored by the European Union Civil Protection Mechanism (EUCPM). As part of the exercise, a crisis response simulation was carried out using drones to support search and rescue operations. Simulation was addressed to a hypothetical country that has been affected by the refugee crisis, as a result of the hurricane, which was followed by floods and landslides. The tests carried out showed that, although drones had limited use in this simulation, they have the potential to become part of a crisis response toolkit for very specific tasks [85].

Valuable experience is also gained from exercises for the needs of research projects. As part of the e-Notice project and the organized international field exercises conducted in 2019 by the CNBOP-PIB consortium and the City of Dortmund Fire Department at a railway siding in Dortmund, a scenario covering an accident of rail tank cars with chemicals was checked. The accident resulted in a fluid leak that was not identified due to incomplete and illegible marking on the tank. For reconnaissance, the UAV equipped with a visible light and thermal imaging camera was used as a support. The event area is shown in the photo below (Figure 1). 


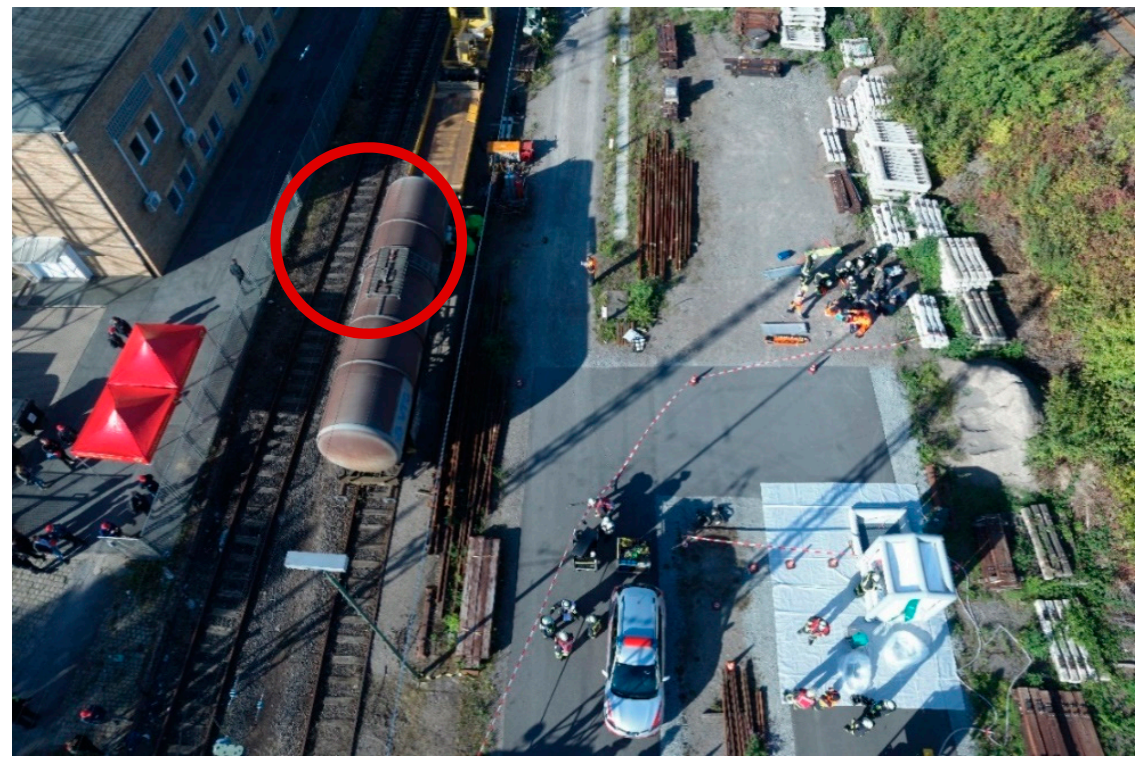

Figure 1. The place of the incident during the exercises in Dortmund during the e-Notice project.

The place of the simulated leakage is marked with a red circle (21.09.2019 Radoslaw Fellner).

Thanks to the RGB camera it was possible, among others, to obtain an image of the scene of the accident, assess the size of the accident, and detect obstacles hindering rescue operations. Remote temperature measurement with a thermal imaging camera allowed to assess whether the adjacent tanks were damaged and whether they were unsealed [86]. The pictures below (Figure 2) show a comparison of images from these two cameras. Pictures was taken by camera E10Tv with a $640 \times 512$ pixel thermal resolution, in RGB (left side) and thermal mode (right side, in rainbow palette), scene range is $-40-550{ }^{\circ} \mathrm{C}$. Considering that it was an exercise, there was no real leakage. A distinctive point that confirmed the simulated leakage was indicated (right side of rail tank cars) as application activity.
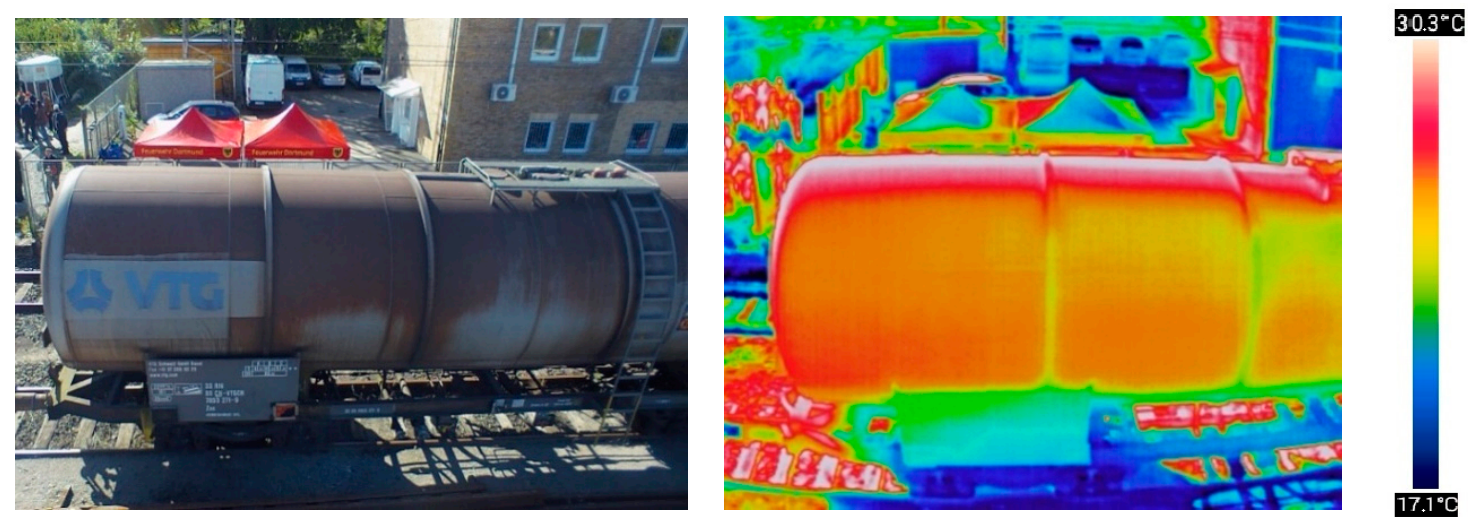

Figure 2. Comparison of images from RGB and thermal imaging cameras-a railway wagon tank (21.09.2019 Radoslaw Fellner).

Research about combating forest fires or mitigating damage caused by fires using early detection methods was carried out, among others, by Kinaneva et al. [87]. Based on UAVs, which are equipped with on-board data processing capabilities, it is possible to constantly patrol possible fire locations which are potentially at risk. Computer vision methods, based on still images or video signals from drone cameras, are used to recognize and detect smoke or fire [86].

Therefore, the prospects for the development and use of UAVs in rescue and fire prevention are very promising. In the future, $\mathrm{UAVs}$ will probably complement the functionalities of fire trucks used in 
the fire brigade, which have the possibility of wireless transmission of the current image of the scene of the event, as well as the transmission of additional information, data, and measurements. In the future, UAVs and their equipment will require less work/maintenance related to their preparation for flight and taking measurements, and the process of sharing the images will be more automated. Effective implementation of these described practical activities will require all organizational units of the State Fire Service that have drones and their additional equipment, primarily system solutions, and these will be created on the basis of exercises, conclusions from thematic workshops with the creation of drone scenarios, and the analysis of actual activities with the use of UAVs during rescue operations-firefighting. Mass use of UAVs is related to obtaining full autonomy by the UAV and its equipment, so that the Commander can independently use the UAV platform, adapted to the rescue needs [88-90]. It should also be added that the research carried out at the Scientific and Research Centre for Fire Protection-National Research Institute (CNBOP-PIB, Józefów, Poland), as part of the project "Controlling an autonomous drone using goggles (monocular)" [25]—showed that the main requirements concern, inter alia, weather conditions in the scope of operating temperature from -30 to $+65^{\circ} \mathrm{C}$, wind speed, flight possibilities during rainfall, as well as functional ones, such as resistance to water, interference, dust, selected chemicals, flight time.

Marques et al. [91] reported the results of GammaEx project based on the emergence of a new concept, addressing the use of UAVs in CBRN operations, considering the environmental context of the explosive atmospheres that could be part of port and maritime incident-based scenarios. Based on near-real scenarios, a UAV with remote sensing capabilities and ATEX compliance was developed. The selected scenarios were very close to the real event because they were selected based on a risk probability analysis. These scenarios with real fire obtained by burning toxic industrial chemicals allowed the testing of detectors under near-real conditions. Such research may be of great importance in rescue operations after explosions such as recently in Lebanon, which took place on 4 August 2020 in the port of Beirut.

An interesting solution is also the possibility of using several integrated different technologies and tools to carry out area monitoring. The integration of the laser network of pollution detectors in conjunction with the system mounted on an unmanned aerial vehicle (UAV) allows for the identification and emission of a given pollutant. The occurrence of an anomaly will activate the drone and the area will be examined by the drone [92]. This solution may be important in the case of chemical industrial plants, where the air quality is important for safety, and the exceeding of permissible standards (e.g., hourly concentration) may define the necessity of evacuation.

UAVs are increasingly used in the monitoring system, allowing the determination of both the temporary, short-term and long-term impact of pollution on humans and the environment. In addition, the possibility of making measurements at intervals of seconds, allows the mapping of the area, the location of the emission source, and tracking the movement of pollutants. This information is necessary not only for ongoing monitoring, but especially in the event of events that threaten the life and safety of people. Information on the distribution of the concentration of a given substance in place and time is important for this type of event. Monitoring based on the UAV allows for immediate information about the risk of exceeding the permissible hourly concentration and thus allows for taking appropriate actions. It is not possible in the case of stationary monitoring based on monitoring stations.

\section{Conclusions}

At present, unmanned aerial vehicles are an important tool in the field of air quality monitoring, identification of hazardous compounds that endanger the health and safety of people and pose a threat to the environment. However, in order for them to be safely and reliably used, it is necessary to take into account such materials and structures of the UAV that will be resistant to environmental conditions occurring during the operation and tested in terms of their actual parameters and functionality.

For the development of the mass use of UAVs, projects and technologies related to the automation of operation, control, and continuing airworthiness are important. Paradoxically, apart from the 
legislation, for the rapid development of UAVs applications, standardization work and the development of product standards are necessary. For rescue applications, there is great potential in combining technologies. An example is the already mentioned project [25] implementation period 2018-2021, under which a dedicated form of drone control using the operator's eyesight is being developed for the purposes of operational activities of the Border Guard. Such research allows revealing new needs and possibilities of available new technologies and their combination. They also allow for the verification of already possible practical applications and those requiring further technology development, e.g., UAV. However, it is important to be aware that the use of each new technology is associated, on the one hand, with new possibilities and functionalities and, on the other hand, with new needs, challenges, and threats. (e.g., drone fall, loss of control, communication, collision, damage, danger, etc.).

The results of the analysis in question may allow for further systematization of formal, legal, research, and operational aspects related to the use of UAVs during activities related to chemical rescue. Until now, there have been no such analyses. This paper also may be the basis for further research and work on the possibility of using UAVs in situations in increased emissions, when knowledge of the air quality at a given moment is so necessary. In the case of the fire brigade, such use may be of particular importance in the case of fires, e.g., landfills or industrial areas, when it is not fully known what material is burned and thus it is difficult to determine what products of combustion will be emitted into the environment. The presented research results also indicate the possibility of using the system of permanent air quality control in specific places, such as landfills, due to the high mobility of the system and the possibility of quick and easy location of areas where additional personal protection or areas at risk of explosion is required. The cited research results and the conducted analysis may also constitute the basis and some inspiration for further activities, research, experiments and, finally, implementation of solutions dedicated to air quality assessment and their use in practice. These studies may reveal further needs for the practical application of such measurements. Among them, it is justified to mention that there is the need for dedicated guidelines about tactics of using UAVs to monitor selected CBRN threats and support for rescue and firefighting operations.

Funding: This research was funded by the National Centre for Research and Development as part of the project entitled "Controlling an autonomous drone using goggles (monocular)", no. DOB-BIO9/26/04/2018.

Conflicts of Interest: The authors declare no conflict of interest.

\section{References}

1. Yinka-Banjo, C.O.; Ajayi, O. Sky-Farmers: Applications of Unmanned Aerial Vehicles (UAV) in Agriculture. Intech 2019, 107-128. [CrossRef]

2. Berie, H.T.; Burud, I. Application of unmanned aerial vehicles in earth resources monitoring: Focus on evaluating potentials for forest monitoring in Ethiopia. Eur. J. Remote Sens. 2018, 51, 326-335. [CrossRef]

3. Otto, A.; Agatz, N.; Campbell, J.; Golden, B.; Pesch, E. Optimization approaches for civil applications of unmanned aerial vehicles (UAVs) or aerial drones: A survey. Networks 2018, 1-48. [CrossRef]

4. Melesse, A.; Weng, Q.; Prasad, S.; Senay, G. Remote Sensing Sensors and Applications in Environmental Resources Mapping and Modelling. Sensors 2007, 7, 3209-3241. [CrossRef] [PubMed]

5. Drones. Reporting for Work. Available online: https://www.goldmansachs.com/insights/technology-drivinginnovation/drones/ (accessed on 6 December 2020).

6. Watson, J. Agriculture Drone Market 2020 CAGR of 22.6\% forecasted for Excellent Revenue Growth USD 6.52 Billion by 2027|Reports and Data. Available online: https://apnews.com/dd8a288a73b2a3d2cfbb8ccd3d045f6b (accessed on 9 September 2020).

7. Available online: https://www.globenewswire.com/news-release/2020/05/29/2041044/0/en/Small-DronesMarket-Size-to-Reach-USD-22-55-Billion-by-2026-Increasing-Deployment-of-UAVs-for-SurveillancePurposes-to-Favor-Market-Growth-Says-Fortune-Business-Insights.html (accessed on 9 September 2020).

8. Castellano, F. Commercial Drones Are Revolutionizing Business Operations. Available online: https: //www.toptal.com/finance/market-research-analysts/drone-market (accessed on 6 December 2020). 
9. Available online: https://www.thefirstnews.com/article/drone-market-facing-staggering-3-billion-pln-boom4579 (accessed on 9 September 2020).

10. Available online: https://polandin.com/41179370/pl-drone-market-to-be-worth-eur-760-mln-in-10-yearsdep-min. (accessed on 9 September 2020).

11. Kim, D.-W.; Min, T.-S.; Kim, Y.; Silva, R.R.; Hyun, H.-N.; Kim, J.-S.; Kim, K.-H.; Kim, H.-J.; Chung, Y.S. Sustainable Agriculture by Increasing Nitrogen Fertilizer Efficiency Using Low-Resolution Camera Mounted on Unmanned Aerial Vehicles. Int. J. Environ. Res. Public Health 2019, 16, 3893. [CrossRef] [PubMed]

12. Yang, F.; Shao, Q.; Jiang, Z. A Population Census of Large Herbivores Based on UAV and Its Effects on Grazing Pressure in the Yellow-River-Source National Park, China. Int. J. Environ. Res. Public Health 2019, 16, 4402. [CrossRef]

13. Giordan, D.; Adams, M.S.; Aicardi, I.; Alicandro, M.; Allasia, P.; Baldo, M.; De Berardinis, P.; Dominici, D.; Godone, D.; Hobbs, P.; et al. The use of unmanned aerial vehicles (UAVs) for engineering geology applications. Bull. Eng. Geol. Environ. 2020, 79, 3437-3481. [CrossRef]

14. Slezak, D.; Tyranska-Fobke, A.; Robakowska, M.; Nowak, J.; Zuratynski, P.; Ladny, J.R.; Kraszewski, J.; Domanska-Sadynica, M.; Nadolny, K. The use of drones in various rescue sectors-An analysis of examples in Poland and in the world. Post N Med. 2018, XXXI, 173-178. [CrossRef]

15. Li, S.; Xiang, Q.; Ma, Y.; Gu, X.; Li, H. Crash Risk Prediction Modeling Based on the Traffic Conflict Technique and a Microscopic Simulation for Freeway Interchange Merging Areas. Int. J. Environ. Res. Public Health 2016, 13, 1157. [CrossRef]

16. Hassanalian, M.; Abdelkefi, A. Classifications, applications, and design challenges of drones: A review. Prog. Aerosp. Sci. 2017, 92, 99-131. [CrossRef]

17. Hoesly, R.M.; Smith, S.J.; Feng, L.; Klimont, Z.; Janssens-Maenhout, G.; Pitkanen, T.; Seibert, J.J.; Vu, L.; Andres, R.J.; Bolt, R.M.; et al. Historical (1750-2014) anthropogenic emissions of reactive gases and aerosols from the Community Emission Data System (CEDS). Geosci. Model Dev. 2018, 11, 369-408. [CrossRef]

18. Yao, Y.; Wei, S.; Zhang, H.; Li, Q. Application of UAV in Monitoring Chemical Pollutant Gases. Chem. Eng. Trans. 2018, 67, 583-588. [CrossRef]

19. Beloev, I.H. A Review on Current and Emerging Application Possibilities for Unmanned Aerial Vehicles. Acta Technol. Agric. 2016, 3, 70-76. [CrossRef]

20. Alvear, O.; Zema, N.R.; Natalizio, E.; Calafate, C.T. Using UAV-Based Systems to Monitor Air Pollution in Areas with Poor Accessibility. J. Adv. Transp. 2017, 2017, 1-14. [CrossRef]

21. Wespes, C.; Emmons, L.; Edwards, D.P.; Hannigan, J.; Hurtmans, D.; Saunois, M.; Coheur, P.F.; Clerbaux, C.; Coffey, M.T.; Batchelor, R.L.; et al. Analysis of ozone and nitric acid in spring and summer Arctic pollution using aircraft, ground-based, satellite observations and MOZART-4 model: Source attribution and partitioning. Atmos. Chem. Phys. 2012, 12, 237-259. [CrossRef]

22. Gallachera, D. Drones to manage the urban environment. Risks, rewards, alternatives. J. Unmanned Vehicle Syst. 2016, 4, 115-124. [CrossRef]

23. Villa, T.F.; Gonzalez, F.; Miljievic, B.; Ristovski, D.; Morawska, L. An Overview of Small Unmanned Aerial Vehicles for Air Quality Measurements: Present Applications and Future Prospectives. Sensors 2016, 16, 1072. [CrossRef]

24. Gaffey, C.; Bhardwaj, A. Applications of Unmanned Aerial Vehicles in Cryosphere: Latest Advances and Prospects. Remote Sens. 2016, 12, 948. [CrossRef]

25. Controlling an Autonomous Drone Using Goggles (Monocular), No. DOB-BIO9/26/04/2018; Project financed by the National Centre for Research and Development: Warszawa, Poland.

26. Whitehead, K.; Hugenholtz, C.H.; Myshak, S.; Brown, O.; LeClair, A.; Tamminga, A.; Barchyn, T.E.; Moorman, B.; Eaton, B. Remote sensing of the environment with small unmanned aircraft systems (UASs), part 2: Scientific and commercial applications. J. Unmanned Veh. Syst. 2014, 2, 86-102. [CrossRef]

27. López, J.J.; Mulero-Pázmány, M. Drones for Conservation in Protected Areas: Present and Future. Drones 2019, 3, 10. [CrossRef]

28. Available online: https://www.pansa.pl/en/polish-air-navigation-services-agency-launched-the-firstoperational-drone-flight-coordination-system-in-europe/ (accessed on 9 September 2020).

29. Available online: https://www.orlen.pl/EN/PressOffice/Pages/Modern-technologies-improve-the-securityof-ORLEN\%E2\%80\%99s-Production-Plant-in-P\%C5\%82ock.aspx (accessed on 9 September 2020). 
30. Sharma, M. How Drones Are Being Used to Combat COVID-19. 2020. Available online: https://www. geospatialworld.net/blogs/how-drones-are-being-used-to-combat-covid-19/ (accessed on 9 September 2020).

31. European Union. Air Quality-Existing Legislation. Available online: https://ec.europa.eu/environment/air/ quality/existing_leg.htm (accessed on 28 July 2020).

32. Joint Report on Air Quality. EUROSAI Working Group on Environmental Auditing; The Netherlands Court of Audit and the Supreme Audit Office of Poland: Warszawa, Poland, 2019.

33. Ncube, M.; Riffat, S. Developing an indoor environment quality tool for assessment of mechanically ventilated office buildings in the UK-A preliminary study. Build. Environ. 2012, 53, 26-33. [CrossRef]

34. Heinzerling, D.; Schiavon, S.; Webster, T.; Arens, E. Indoor environmental quality assessment models: A literature review and a proposed weighting and classification scheme. Build. Environ. 2013, 70, $210-222$. [CrossRef]

35. Mihai, T.; Iordache, V. Determining the indoor environment quality for an educational building. Energy Procedia 2016, 85, 566-574. [CrossRef]

36. McWilliams, J. Review of Airflow Measurement Techniques Lawrence Berkeley National Laboratory 2002-12-01. Available online: https://escholarship.org/uc/item/7532b84f (accessed on 27 May 2020).

37. Weitkamp, C. (Ed.) Lidar Range-Resolved Optical Remote Sensing of the Atmosphere; Springer Science+Business Media Inc.: Berlin/Heidelberg, Germany, 2005.

38. Nishizawa, T.; Sugimoto, N.; Matsui, I.; Shimizu, A.; Tatarov, B.; Okamoto, H. Algorithm to Retrieve Aerosol Optical Properties from High-Spectral-Resolution Lidar and Polarization Mie-Scattering Lidar Measurements. IEEE Trans. Geosci. Remote Sens. 2008, 46, 4094-4103. [CrossRef]

39. Amiridis, V.; Balis, D.S.; Giannakaki, E.; Stohl, A.; Kazadzis, S.; Koukouli, M.E.; Zanis, P. Optical characteristics of biomass burning aerosols overSoutheastern Europe determined from UV-Raman lidarmeasurements. Atmos. Chem. Phys. 2009, 9, 2431-2440. [CrossRef]

40. Koch, G.J.; Barnes, B.W.; Petros, M.; Beyon, J.Y.; Amzajerdian, F.; Yu, J.; Davis, R.E.; Ismail, S.; Vay, S.; Kavaya, M.J.; et al. Coherent differential absorption lidar measurements of $\mathrm{CO}_{2}$. Appl. Opt. 2004, 43, 5092-5099. [CrossRef]

41. Collier, C.G.; Davies, F.; Bozier, K.E.; Holt, A.R.; Middleton, D.R.; Pearson, G.N.; Siemen, S.; Willetts, D.V.; Upton, G.J.G.; Young, R.I. Dual-Doppler Lidar Measurements for Improving Dispersion Models. Bull. Amer. Meteor. Soc. 2005, 86, 825-838. [CrossRef]

42. Arnold, K.S.; She, C.Y. Metal Fluorescence lidar (light detection and ranging) and the middle atmosphere. Contemp. Phys. 2003, 44, 35-49. [CrossRef]

43. Gaudio, P.; Gelfusa, M.; Malizia, A.; Parracino, S.; Richetta, M.; De Leo, L.; Perrimezzi, C.; Bellecci, C. Detection and monitoring of pollutant sources with Lidar/Dial techniques. J. Phys. Conf. Ser. 2015, 658, 1-9. [CrossRef]

44. Mcdermott, H.J. Air Monitoring for Toxic Exposures; Wiley Interscience: Hoboken, NJ, USA, 2004; ISBN 0-471-45435-4.

45. Knake, R.; Hauser, P.C. Sensitive electrochemical detection of ozone. Anal. Chim. Acta 2002, 459, $199-207$. [CrossRef]

46. Roldán, J.J.; Joossen, G.; Sanz, D.; del Cerro, J.; Barrientos, A. Mini-UAV based sensory system for measuring environmental variables in greenhouses. Sensors 2015, 15, 3334-3350. [CrossRef] [PubMed]

47. Giurgiutiu, V. Structural Health Monitoring with Piezoelectric Wafer Active Sensors. In Proceedings of the 16th International Conference of Adaptive Structures and Technologies ICAST-2005, Paris, France, 10-12 October 2005.

48. Bársony, I.; Dücső, C.; Fürjes, P. Thermometric Gas Sensing. In Solid State Gas Sensing; Comini, E., Faglial, G., Sberveglieri, G., Eds.; Springer Science+Bisoness Media, LLC: Boston, MA, USA, 2009; ISBN 978-0-387-09664-3.

49. Hofman, J.; Maher, B.A.; Muxworthy, A.R.; Wuyts, K.; Castanheiro, A.; Samson, R. Biomagnetic monitoring of atmospheric pollution: A review of magnetic signatures from biological sensors. Environ. Sci. Technol. 2017, 51, 6648-6664. [CrossRef] [PubMed]

50. Rutkauskas, M.; Asenov, M.; Ramamoorthy, S.; Reid, D.T. Autonomous multi-species environmental gas sensing using drone-based Fourier-transform infrared spectroscopy. Opt. Express 2019, 27, 9578-9587. [CrossRef] [PubMed] 
51. Rossi, M.; Brunelli, D. Autonomous Gas Detection and Mapping with Unmanned Aerial Vehicles. IEEE Trans. Instrum. Meas. 2015, 65, 765-775. [CrossRef]

52. Kas, K.A.; Johnson, G.K. Using unmanned aerial vehicles and robotics in hazardous locations safely. Proc. Safety Prog. 2020, 39, e12066. [CrossRef]

53. Available online: https://drones4safety.eu/ (accessed on 9 September 2020).

54. Available online: http://labyrinth2020.eu/ (accessed on 9 September 2020).

55. Available online: https://wzl2.mil.pl/en/about-us/eu-grants-projects/\#1528886676139-2f7a66a1-9277 (accessed on 9 September 2020).

56. ISO 21384-3:2019 Unmanned Aircraft Systems-Part 3: Operational Procedures; Reference Number ISO 21384-3:2019(E); CP 401. Ch. de Blandonnet 8. CH-1214; ISO Copyright Office: Vernier, Geneva, 2019; p. 18.

57. ISO 21384-4:2020 Unmanned Aircraft Systems-Part 4: Vocabulary; Reference number ISO 21384-4:2020(E); CP 401. Ch. de Blandonnet 8. CH-1214; ISO copyright office: Vernier, Geneva, 2020; p. 10.

58. ISO 21895: 2020 Categorization and Classification of Civil Unmanned Aircraft Systems; Reference Number ISO 21895-2020(E); CP 401. Ch. de Blandonnet 8. CH-1214; ISO Copyright Office: Vernier, Geneva, 2020; p. 7.

59. ISO/TR 23629-1: 2020 UAS Traffic Management (UTM)-Part 1: Survey Results on UTM; Reference Number ISO/TR 23629-1:2020(E); CP 401. Ch. de Blandonnet 8. CH-1214; ISO Copyright Office: Vernier, Geneva, 2020; p. 15.

60. Standardization Roadmap for Unmanned Aircraft Systems-Working Draft, Version 2.0, Unmanned Aircraft Systems Standardization Collaborative (UASSC), UASSC 20-001; American National Standards Institute (ANSI): Washington, DC, USA, 2020; p. 356.

61. Reneke, P.; Grant, C.; Bryner, N.P.; Jones, A.W.; Koepke, G.H. Research Roadmap for Smart Fire Fighting; National Institute of Standards and Technology (NIST): Gaithersburg, MD, USA, 2015. [CrossRef]

62. Available online: https://www.flir.com/products/muve-c360/ (accessed on 7 December 2020).

63. Available online: https://scentroid.com/products/analyzers/dr1000-flying-lab/ (accessed on 7 December 2020).

64. Available online: https://aeromind.pl/product-eng-11475-Atmon-FL-Air-pollution-analyser.html (accessed on 7 December 2020).

65. Available online: https://www.flir.com/products/zenmuse-xt2/ (accessed on 29 June 2020).

66. Available online: https://www.gemsys.ca/uav-systems/ (accessed on 29 June 2020).

67. Available online: https://www.gemsys.ca/uav-platforms/ (accessed on 29 June 2020).

68. Available online: https://www.maxbotix.com/ultrasonic-sensor-operation-uav.htm (accessed on 29 June 2020).

69. Available online: https://micasense.com/rededge-mx/ (accessed on 29 June 2020).

70. Available online: https://www.flycamuav.com/product/dronerad-detector-systems/ (accessed on 29 June 2020).

71. Available online: https://www.sensichips.com/smart-cable-air/ (accessed on 29 June 2020).

72. Available online: https://cordis.europa.eu/project/id/674434/reporting (accessed on 29 June 2020).

73. European Commission. Directive 2014/34/EU of the European Parliament and of the Council of 26 February 2014 on the Harmonisation of the Laws of the Member States Relating to Equipment and Protective Systems Intended for use in Potentially Explosive Atmospheres; European Commission: Brussels, Belgium, 2014; pp. 309-356.

74. Aiello, G.; Hopps, F.; Santisi, D.; Venticinque, M. The Employment of Unmanned Aerial Vehicles for Analyzing and Mitigating Disaster Risks in Industrial Sites. IEEE 2020, 67, 519-530. [CrossRef]

75. Ferlin, M.; Kurela, M.; Monge, O.; Castgnet, C. Smart Operations in ATEX RLV Environment. In Proceedings of the 8th European Conference for Aeronautics and Space Sciences (EUCASS), Madrid, Spain, 1-4 July 2019; pp. 1-13. [CrossRef]

76. Available online: http://www.hazardexonthenet.net/article/121803/Drone-operations-in-hazardous-areas. aspx (accessed on 26 September 2020).

77. European Commission. ANNEX I-CLASSIFICATION OF PLACES WHERE EXPLOSIVE ATMOSPHERES MAY OCCUR, Directive 1999/92/EC of the European Parliament and of the Council of 16 December 1999 on Minimum Requirements for Improving the Safety and Health Protection of Workers Potentially at Risk from Explosive Atmospheres; European Commission: Brussels, Belgium, 2020.

78. GAZ SYSTEM. Sustainable Development Report. 2018. Available online: https://en.gaz-system.pl/fileadmin/ centrum_prasowe/wydawnictwa/EN/AnnualRaport2018_www.pdf (accessed on 28 July 2020).

79. Available online: http://www.hazardexonthenet.net/article/65112/Poland-gas-pipeline-explosion-kills-3-injures-10.aspx (accessed on 28 July 2020). 
80. Restas, A. Drone applications for preventing and responding HAZMAT disaster. World J. Eng. Technol. 2016, 4, 76-84. [CrossRef]

81. Auburn, L.; Researchers Using Drones to Detect Noxious Gas Released by Explosions. Rochester Institute of Technology/News. 2020. Available online: https://www.rit.edu/news/researchers-using-drones-detectnoxious-gas-released-explosions (accessed on 28 July 2020).

82. Everts, S.; Davenport, M. Drones detect threats such as chemical weapons, volcanic eruptions. CEN Glob. Enterp. 2016, 94, 36-37. [CrossRef]

83. Available online: https://pelixar.com/unmanned-systems/?lang=en (accessed on 6 December 2020).

84. Marturano, F.; Ciparisse, J.-F.; Chierici, A.; d'Errico, F.; Di Giovanni, D.; Fumian, F.; Rossi, R.; Martellucci, L.; Gaudio, P.; Malizia, A. Enhancing Radiation Detection by Drones through Numerical Fluid Dynamics Simulations. Sensors 2020, 20, 1770. [CrossRef]

85. Drones in Humanitarian Action. Case Study No.11: Natural disaster/Acute emergency/Search and Rescue. Simulation-Drones for Search and Rescue in Emergency Response Simulation. Available online: https://reliefweb.int/sites/reliefweb.int/files/resources/Drones\%20in\%20Humanitarian\% 20Action\%20-\%20Case\%20Study\%2011\%20-\%20Search\%20and\%20Rescue\%20Trimodex.pdf (accessed on 9 September 2020).

86. eNOTICE Newsletter 2. 22 January 2020. Available online: https://cloud.h2020-enotice.eu/index.php/s/ newsletter2\#pdfviewer (accessed on 9 September 2020).

87. Kinaneva, D.; Hristov, G.; Raychev, J.; Zahariev, P. Early Forest Fire Detection Using Drones and Artificial Intelligence. Computer Science. In Proceedings of the 42nd International Convention on Information and Communication Technology, Electronics and Microelectronics (MIPRO), Rijeka, Croatia, 20-24 May 2019. [CrossRef]

88. Available online: https://www.geoscan.aero/en/products/choose_uav (accessed on 9 September 2020).

89. Shakhatreh, H.; Sawalmeh, A.; Al-Fuqaha, A.; Dou, Z.; Almaita, E.; Khalil, I.; Othman, N.S.; Khreishah, A.; Guizan, M. Unmanned Aerial Vehicles: A Survey on Civil Applications and Key Research Challenges. Available online: https://arxiv.org/pdf/1805.00881.pdf (accessed on 9 September 2020).

90. Pepe, M.; Fregonese, L.; Scaioni, M. Planning airborne photogrammetry and remote-sensing missions with modern platforms and sensors. Eur. J. Remote. Sens. 2018, 51, 412-436. [CrossRef]

91. Marques, M.M.; Carapau, R.S.; Rodrigues, A.V.; Lobo, V.; Gouveia-Carvalho, J.; Antunes, W.; Gonçalves, T.; Duarte, F.; Verissimo, B. GammaEx project: A solution for CBRN remote sensing using unmanned aerial vehicles in maritime environments. In Proceedings of the OCEANS 2017, Anchorage, AK, USA, 18-21 September 2017.

92. Fumian, F.; Di Giovanni, D.; Martellucci, L.; Rossi, R.; Gaudio, P. Application of Miniaturized Sensors to Unmanned Aerial Systems, A New Pathway for the Survey of Polluted Areas: Preliminary Results. Atmosphere 2020, 11, 471. [CrossRef]

Publisher's Note: MDPI stays neutral with regard to jurisdictional claims in published maps and institutional affiliations.

(C) 2020 by the authors. Licensee MDPI, Basel, Switzerland. This article is an open access article distributed under the terms and conditions of the Creative Commons Attribution (CC BY) license (http://creativecommons.org/licenses/by/4.0/). 